\title{
Brain Activation during Human Male Ejaculation
}

\author{
Gert Holstege, ${ }^{1}$ Janniko R. Georgiadis, ${ }^{1}$ Anne M. J. Paans, ${ }^{2}$ Linda C. Meiners, ${ }^{3}$ Ferdinand H. C. E. van der Graaf, ${ }^{4}$ and \\ A. A. T. Simone Reinders ${ }^{5}$ \\ ${ }^{1}$ Department of Anatomy and Embryology, University of Groningen, 9713 AV Groningen, The Netherlands, and ${ }^{2}$ Positron Emission Tomography Centre \\ and Departments of ${ }^{3}$ Radiology, ${ }^{4}$ Neurology, and ${ }^{5}$ Biological Psychiatry, University Hospital Groningen, 9713 AV Groningen, The Netherlands
}

Brain mechanisms that control human sexual behavior in general, and ejaculation in particular, are poorly understood. We used positron emission tomography to measure increases in regional cerebral blood flow ( $\mathrm{rCBF}$ ) during ejaculation compared with sexual stimulation in heterosexual male volunteers. Manual penile stimulation was performed by the volunteer's female partner. Primary activation was found in the mesodiencephalic transition zone, including the ventral tegmental area, which is involved in a wide variety of rewarding behaviors. Parallels are drawn between ejaculation and heroin rush. Other activated mesodiencephalic structures are the midbrain lateral central tegmental field, zona incerta, subparafascicular nucleus, and the ventroposterior, midline, and intralaminar thalamic nuclei. Increased activation was also present in the lateral putamen and adjoining parts of the claustrum.

Neocortical activity was only found in Brodmann areas $7 / 40,18,21,23$, and 47, exclusively on the right side. On the basis of studies in rodents, the medial preoptic area, bed nucleus of the stria terminalis, and amygdala are thought to be involved in ejaculation, but increased rCBF was not found in any of these regions. Conversely, in the amygdala and adjacent entorhinal cortex, a decrease in activation was observed.

Remarkably strong rCBF increases were observed in the cerebellum. These findings corroborate the recent notion that the cerebellum plays an important role in emotional processing. The present study for the first time provides insight into which regions in the human brain play a primary role in ejaculation, and the results might have important implications for our understanding of how human ejaculation is brought about, and for our ability to improve sexual function and satisfaction in men.

Key words: amygdala; cerebellum; heroin; midbrain; PET (positron emission tomography); sex

\section{Introduction}

The recent success of drugs that increase male sexual performance emphasizes the enormous impact of sexual function on the overall quality of life. Ejaculation represents a major component of male sexual behavior. It is the result of a coordinated action of male sexual organs such as the prostate, seminal vesicles, urethra, and pelvic floor muscles (Gil-Vernet et al., 1994) and is typically accompanied by orgasmic sensations.

Studies in rats and gerbils have revealed that the medial preoptic area (MPOA), medial nucleus of the amygdala (MeA), bed nucleus of the stria terminalis (BNST), midbrain lateral central tegmental field (LCTF), and parvocellular part of the subparafascicular nucleus (SPFp) express Fos activity with ejaculation (Baum and Everitt, 1992; Coolen et al., 1996; Heeb and Yahr, 1996). In primates, however, a decrease in c-Fos activity was found in the BNST and hypothalamic regions (Michael et al., 1999). Baum and Everitt (1992) suggest that in rats, genital and olfactory vomeronasal input induces c-Fos activity in the LCTF/ SPFp and MeA, respectively, and that these regions, in turn, ac-

\footnotetext{
Received May 26, 2003; revised July 16, 2003; accepted Aug. 12, 2003.

We thank C. A. Jaspers (a member of the board of the University Hospital Groningen) and R. T. Meijer for their help in performing this study. We are especially indebted to members and staff of the PET and MRI centers of the Academic Hospital Groningen.

Correspondence should be addressed to Dr. Gert Holstege, Department of Anatomy and Embryology, University of Groningen, A. Deusinglaan 1, 9713 AV Groningen, The Netherlands. E-mail: g.holstege@med.rug.nl.

Copyright $\odot 2003$ Society for Neuroscience $\quad 0270-6474 / 03 / 239185-09 \$ 15.00 / 0$
}

tivate the MPOA and BNST. Lesions in the posterodorsal preoptic nucleus and posterodorsal MeA in gerbils (Heeb and Yahr, 2000) resulted in a delay in ejaculation, but lesions in the subparafascicular nucleus did not. In male rats, bilateral lesions in the area of the LCTF completely eliminated mating behavior (Brackett and Edwards, 1984), as was the case after a unilateral MPOA lesion combined with a lesion in the LCTF on the contralateral side. Apparently, in rodents, connections between the MPOA and LCTF are essential for copulation.

These studies did not elucidate the precise role of the respective regions in sexual behavior. There are two reasons for the problems with determining the precise role of c-Fos in these events: (1) c-Fos has a temporal resolution of $>1 \mathrm{hr}$ and, therefore, cannot be conclusively linked to one specific event. (2) There is a difference in sensitivity to c-Fos between different brain structures (Kovács, 1998). The impact of lesion studies is also limited, because they do not provide insight into which systems become dysfunctional as a result of various lesions. In conclusion, even in rodents, a complete concept regarding the sensory and motor systems involved in ejaculation is still lacking. In other species, however, almost nothing is known about the cerebral organization of ejaculation.

With the introduction of positron emission tomography (PET) and functional magnetic resonance imaging (fMRI) it became possible to register and map activity in all parts of the human brain, including the brainstem. Several investigators have 
Table 1. Time of ejaculation

\begin{tabular}{|c|c|c|c|c|}
\hline \multirow[b]{2}{*}{ Volunteer } & \multicolumn{2}{|l|}{ Ejaculation 1} & \multicolumn{2}{|l|}{ Ejaculation 2} \\
\hline & Seconds after $\mathrm{T}_{0}$ & Frames & Seconds after $\mathrm{T}_{0}$ & Frames \\
\hline 1 & 51 & $5+6$ & & \\
\hline 2 & & & & \\
\hline 3 & 73 & & & \\
\hline 4 & 71 & & & \\
\hline 5 & 35 & $3+4$ & 32 & $3+4$ \\
\hline 6 & 74 & & 48 & $4+5$ \\
\hline 7 & 55 & $5+6$ & 60 & $6+7$ \\
\hline 8 & 60 & $6+7$ & & \\
\hline 9 & & & & \\
\hline 10 & 34 & $3+4$ & & \\
\hline 11 & & & & \\
\hline
\end{tabular}

Each volunteer tried to ejaculate twice (left and right column). The moment of ejaculation is measured in seconds after tracer injection $\left(\mathrm{T}_{0}\right)$, and the selected time frames are shown. When volunteers ejaculated $>70$ sec after $\mathrm{T}_{0}$, the corresponding time frames were not included in the present study.

studied brain activation during human sexual arousal (Stoleru et al., 1999; Redouté et al., 2000; Bocher et al., 2001; Arnow et al., 2002; Karama et al., 2002). The present study is the first to reveal the brain regions in humans that are most active during ejaculation.

\section{Materials and Methods}

Participants. Eleven healthy right-handed heterosexual male volunteers (mean age, 33; range, 19-45) gave written informed consent according to the Declaration of Helsinki, and the procedures were approved by the Groningen University Hospital Medical Ethics Committee. None of the volunteers had any history of physical, psychiatric, and sexual disorders. All volunteers, regardless of their performance, received a modest reimbursement of travel expenses but no honorarium.

PET protocol. Measurements were made with an Ecat Exact HR+ (CTI/Siemens, Knoxville TN). This 32 ring PET scanner with an axial field of view of $15.5 \mathrm{~cm}$ was operated in three-dimensional mode to have maximum sensitivity of the system. A total of 63 planes were imaged simultaneously. Spatial resolution is $4-5 \mathrm{~mm}$ full-width half-maximum (FWHM) in all three directions. To allow for the decay of the ${ }^{15} \mathrm{O}$ (half life, $122 \mathrm{sec}$ ), the consecutive scans were made with an interval of $\sim 10$ min. For each scan, $500 \mathrm{MBq}$ of $\left[{ }^{15} \mathrm{O}\right]$ water in saline was injected into the right median antebrachial vein and flushed with saline (total volume, $32 \mathrm{ml}$ ) at a speed of $8 \mathrm{ml} / \mathrm{sec}$. Except for the first scan, PET scanning began $30 \mathrm{sec}$ before the injection to acquire background correction information. After injection of the radioactive bolus, data were collected for a duration of $2 \mathrm{~min}$. A scan-specific calculated attenuation correction was performed to minimize interscan displacement-induced variance (Reinders et al., 2002).

Tasks. The volunteers were asked to perform the following tasks twice: rest, erection, sexual stimulation, and ejaculation induced by sexual stimulation. To minimize motor activity by the volunteer during the scan, sexual stimulation was provided by his female partner by means of manual penile stimulation in the tasks stimulation and ejaculation. Manual stimulation was continued throughout ejaculation. The volunteer's head was maintained in position with a head-restraining adhesive band, and, to minimize visual input, volunteers were asked to keep their eyes closed.

In the week before the experiments, the volunteers and their female partners were informed about how the experiments would be conducted, and they were asked to practice at home, especially regarding minimizing head and limb movements. Before the experiment, the precise procedure was again extensively discussed with the volunteers and their female partners. Great effort was made to let the volunteers feel relaxed during the experiments. When asked for their emotional experiences during the tasks, the volunteers did not report important differences between their sexual experience under normal circumstances and in the scanner. All volunteers reported to have used visual imagery to better perform the tasks, and that stimulation and ejaculation were accompanied by pleasurable sensations. Eventually, five of them ejaculated once, three others ejaculated twice, and three volunteers did not succeed (Table 1).

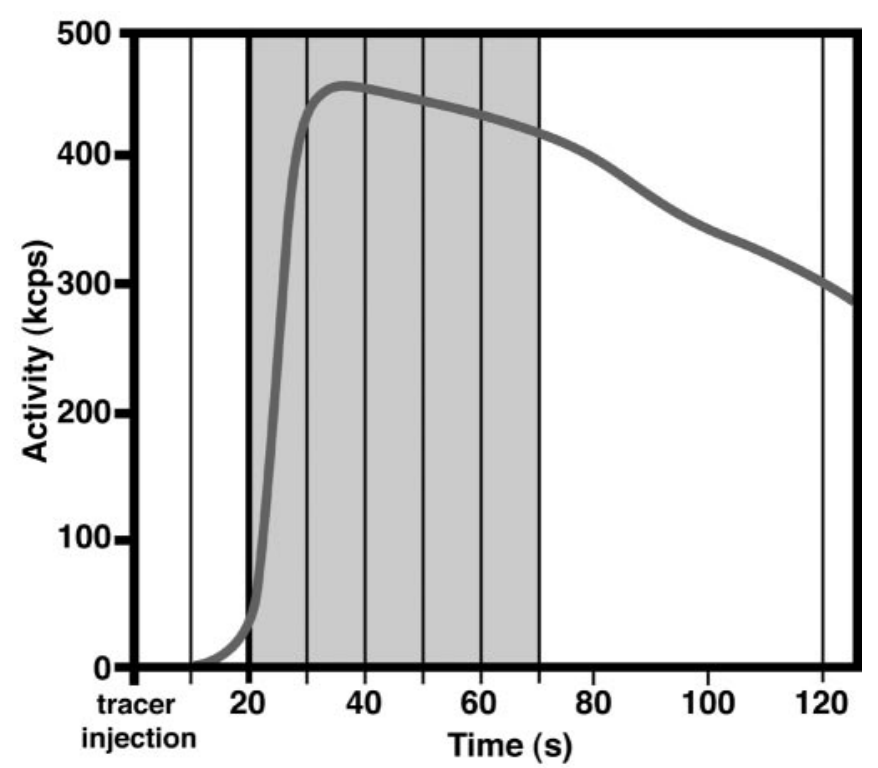

Figure 1. Protocol for the ejaculation condition. The bold black line shows a typical timeactivity curve. Vertical lines indicate time frames of $10 \mathrm{sec}$. Ejaculation took place within the early phase of the time-activity curve, as indicated by gray shading. kcps, Kilocounts per second.

Protocol for ejaculation. The volunteers performed each of the first three tasks (rest, erection, and sexual stimulation) for $2 \mathrm{~min}$, the total duration of a $\left[{ }^{15} \mathrm{O}\right]$ scan. The ejaculation task differed from the other three tasks in respect to its length, which, obviously, is much shorter than 2 min (Gil-Vernet et al., 1994). To more precisely analyze the data around the actual moment of ejaculation, data acquisition was performed in multiple $10 \mathrm{sec}$ frames (Silbersweig et al., 1994). For each ejaculation, two $10 \mathrm{sec}$ frames were selected, summed, and used for subsequent analysis: the time frame in which seminal expulsion, corrected for a $5 \mathrm{sec}$ delay between neuronal activity and regional cerebral blood flow (rCBF) response (Jueptner and Weiler, 1995), took place, together with the preceding time frame (Table 1, Fig. 1). Selection of these two time frames approximately reflects the estimated length of human ejaculation (Gil-Vernet et al., 1994). Because $\left[{ }^{15} \mathrm{O}\right]$ water diffuses into the brain tissue most effectively during the first half of the 2 min scan, the volunteers were asked to ejaculate within the first $50 \mathrm{sec}$ after the arrival of tracer in the brain, which is $\sim 20 \mathrm{sec}$ after tracer injection [Silbersweig et al. (1993), their Fig. 1, gray area]. Eventually, 11 ejaculations were obtained, of which eight were timed successfully (Table 1); these eight were used for additional analysis.

Data processing and statistical analysis. The 1999 version of Statistical Parametric Mapping (SPM99) software was used for spatial transformation (realignment, normalization, and spatial smoothing using an isotropic Gaussian kernel of $10 \mathrm{~mm}$ FWHM) and statistical analysis of the data (Talairach and Tournoux, 1988; Friston et al., 1995a,b). The data were normalized for global effects by proportional scaling (multisubject, conditions and covariates). Although in the present paper we only describe two of the four conditions, all four were used to estimate the variance. The significance of differences in rCBF is assessed using multiple univariate regression analyses. Hypothesized differences in regional cerebral activity attributable to task-related region-specific effects can be tested by performing a Student's $t$ test on each voxel of the brain using regression parameters. Condition-specific effects can be assessed by setting specific contrasts on the parameter estimates, testing against a null hypothesis, which states that there is no difference between conditions tested. Activations are based on the contrast ejaculation minus sexual stimulation, and were examined at a very conservative significance threshold of $p<$ 0.01 , corrected for multiple comparisons with a voxel threshold of $\geq 8$. Significant effects are reported as $\mathrm{z}$-scores (conversion of $t$ statistics to normal distribution) in Table 2 and displayed as $t$ statistics in the statistical parametric maps (SPMs) (see Figs. 2-7). 
Table 2. Stereotaxic (Montreal Neurological Institute) coordinates of increases and decreases in rCBF during ejaculation compared with penile stimulation

\begin{tabular}{|c|c|c|c|c|c|}
\hline \multirow{2}{*}{ Side } & \multirow[b]{2}{*}{ Brain region } & \multicolumn{3}{|c|}{ Coordinates } & \multirow[b]{2}{*}{$z$-score } \\
\hline & & $x$ & $y$ & $z$ & \\
\hline \multicolumn{6}{|c|}{$\begin{array}{l}\text { Activations } \\
\text { Brainstem }\end{array}$} \\
\hline Right & Medial pontomesencephalic tegmentum & 2 & -28 & -22 & 5.80 \\
\hline Left & Lateral pontine tegmentum & -18 & -14 & -34 & 6.69 \\
\hline Right & Lateral pontine tegmentum & 14 & -28 & -30 & 5.28 \\
\hline \multicolumn{5}{|c|}{ Thalamus/midbrain } & 5.48 \\
\hline Left & Mesodiencephalic junction & -8 & -24 & 0 & 7.75 \\
\hline Right & Mesodiencephalic junction & 12 & -24 & 0 & 6.53 \\
\hline $\begin{array}{l}\text { Right } \\
\text { Basal }\end{array}$ & Anterior thalamus & 12 & -4 & 6 & 6.03 \\
\hline Right & Claustrum/insula & 34 & 14 & -8 & 6.21 \\
\hline Left & Claustrum/putamen & -32 & 6 & 4 & 6.28 \\
\hline Right & Claustrum/putamen & 32 & 6 & 0 & 6.50 \\
\hline \multicolumn{2}{|c|}{ Cortical areas } & 20 & 4 & 8 & 5.38 \\
\hline Left & Inferior occipital gyrus (BA 18) & -2 & -100 & -4 & 5.20 \\
\hline Right & Lingual gyrus (BA 18) & 4 & -86 & -12 & 6.22 \\
\hline Midline & Lingual gyrus (BA 18) & 0 & -92 & -6 & 5.74 \\
\hline Right & Precuneus/post. cingulate (BA 31/23) & 16 & -62 & 24 & 6.38 \\
\hline Right & Precuneus (BA 7) & 8 & -54 & 50 & 6.05 \\
\hline Right & Supramarginal gyrus (BA 40) & 52 & -48 & 28 & 7.70 \\
\hline Right & Inferior parietal lobule (BA 40) & 28 & -38 & 50 & 5.39 \\
\hline Right & Paracentral lobule (BA 5) & 18 & -26 & 58 & 5.93 \\
\hline Right & Frontal dorsal gyrus (BA 6) & 16 & 4 & 60 & 5.88 \\
\hline Left & Superior/medial frontal gyrus (BA 6) & -30 & -4 & 64 & 5.61 \\
\hline Right & Superior temporal gyrus (BA 39) & 54 & -60 & 36 & 7.05 \\
\hline Right & Temporal operculum (BA 42) & 52 & -28 & 12 & 6.20 \\
\hline Right & Inferior temporal gyrus (BA 20/21) & 64 & -6 & -32 & 6.33 \\
\hline Right & Insula & 44 & 14 & 12 & 5.54 \\
\hline Right & Inferior frontal gyrus (BA 47) & 54 & 44 & -12 & 7.03 \\
\hline $\begin{array}{l}\text { Right } \\
\text { Cereb }\end{array}$ & Inferior frontal gyrus (BA 47) & 56 & 38 & -6 & 6.71 \\
\hline Left & Deep cerebellar nuclei & -6 & -44 & -24 & 5.88 \\
\hline Left & Deep cerebellar nuclei & -8 & -52 & -30 & 5.31 \\
\hline Left & Vermis & -4 & -88 & -28 & 5.33 \\
\hline Right & Vermis & 2 & -58 & -4 & 6.61 \\
\hline Right & Vermis & 2 & -66 & -32 & 6.47 \\
\hline Left & Hemisphere & -34 & -58 & -40 & 7.38 \\
\hline Left & Hemisphere & -30 & -84 & -34 & 7.19 \\
\hline Right & Hemisphere & 32 & -68 & -46 & 6.55 \\
\hline \multicolumn{6}{|c|}{ Deactivations } \\
\hline Left & Entorhinal cortex & -16 & 0 & -38 & 4.34 \\
\hline Left & Entorhinal cortex & -18 & 10 & -32 & 3.91 \\
\hline Left & Amygdala & -18 & 2 & -24 & 3.34 \\
\hline
\end{tabular}

The height threshold for activations was $t=6.09$ ( $p<0.01$; corrected for multiple comparisons) and for deactivations $t=3.21$ ( $p<0.001$; uncorrected for multiple comparisons; extent threshold 8 voxels). Activations and deactivation are reported in the table as $z$-scores (conversion of $t$ statistics to normal distribution). After transformation to Talairach coordinates, the cortical regions were identified using the Talairach atlas (Talairach and Tournoux, 1988). The thalamic and rostral midbrain structures were identified according to the stereotactic atlas of the human brain by Mai et al. (1997).

Deactivations were based on the contrast sexual stimulation minus ejaculation. They were examined at a significance threshold of $p<0.001$ uncorrected for multiple comparisons with a voxel threshold of $\geq 8$, because at significance thresholds of $p<0.01$ or $p<0.05$ (corrected for multiple comparisons), deactivations were not found.

Anatomical MRIs. Individual MRIs were obtained with a $1.5 \mathrm{~T}$ Siemens Vision magnetic resonance scanner and then normalized and averaged to acquire an accurate template for projection of the PET activations. This template was very similar to the mean $\mathrm{rCBF}$ image of all scans but was preferred because of its higher resolution.

\section{Results}

In eleven healthy right-handed heterosexual male volunteers, rCBF was measured during ejaculation and associated feelings of orgasm. Because ejaculation is a result of stimulation, we first scanned sexual stimulation without achieving ejaculation and the resulting scans were compared with scans in which ejaculation had taken place. Thus, the emerging activation pattern (Table 2,
Fig. 2) is based primarily on the ejaculation/orgasm and not on the stimulation event.

The most intense area of activation was at the mesodiencephalic transition zone (see Figs. 3, 4, 7), which encompasses several structures, including the midline, ventroposterior, and intralaminar thalamic nuclei, subparafascicular nucleus, zona incerta, LCTF, and ventral tegmental area (VTA).

In the telencephalon, increased $\mathrm{rCBF}$ was observed bilaterally in the claustrum and adjoining parts of the rostral insula as well as in the striatum (ventrolateral putamen) (Fig. $5 a-c$ ). Increased $\mathrm{rCBF}$ was also found in the anterior nucleus of the right thalamus (Fig. $5 c, d$ ). In the neocortex, the activated regions were primarily on the right side (Fig. 6), and increased $\mathrm{rCBF}$ was seen in the inferior frontal gyrus [Brodmann area (BA) 47], in parts of the parietal cortex (BA 7 and 40), and in the inferior temporal cortex (BA 20 and 21). Increased activation was also present in the pre- 
sagittal

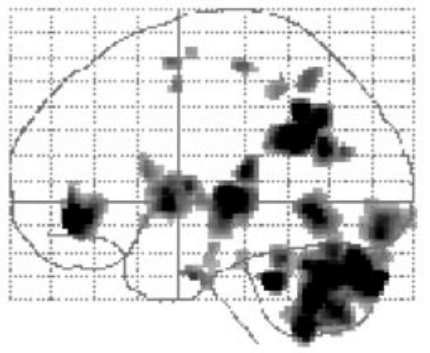

coronal

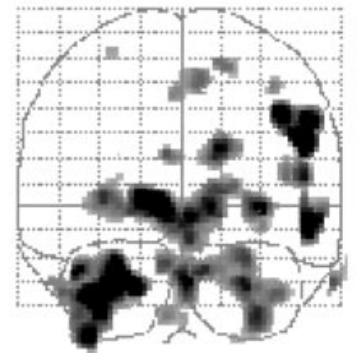

horizontal

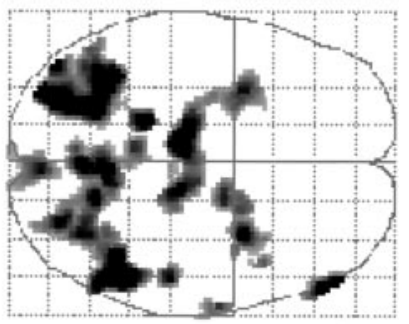

Figure 2. So-called glass brains for ejaculation minus stimulation. Activations are shown in a sagittal, coronal, and horizontal orientation.
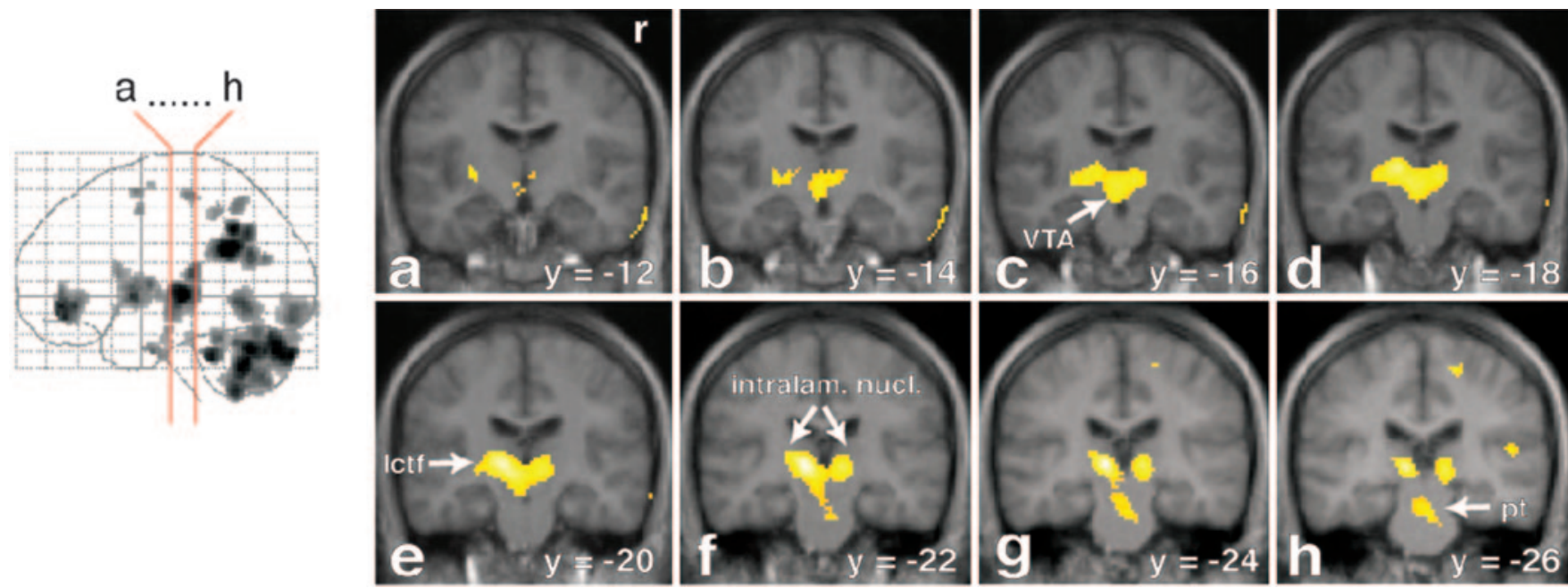

Figure 3. Strong activation in the mesodiencephalic transition zone. Increased rCBF is represented in coronal sections $(a-h)$ through the brain. The red lines on the glass brain on the left indicate the orientation and location of the sections. Activations are superimposed on the averaged MRI of the volunteers. The activated cluster contains the VTA (sections $a-d$ ). The midline thalamic nuclei are located slightly more caudally (sections $d-f$ ). The lateral central tegmental field (Ictf; sections $c-f$ ) and the zona incerta are located lateral to this area. The activated region extends dorsally into the intralaminar nuclei (intralam. nucl.; sections $d-h$ ) and the ventroposterior thalamus. Note also the activation in the medial pontine tegmentum (pt; sections $g$ and $h$ ). $y=-14$ (means $14 \mathrm{~mm}$ posterior to the anterior commissure). r, Right side.

cuneus (BA 23/31) (Fig. 7c). In the left hemisphere (Fig. 6), increased $\mathrm{rCBF}$ was only found in a small portion of the superior frontal gyrus (BA 6). The visual cortex (BA 18) showed increased rCBF bilaterally (Fig. 7b), despite the fact that the volunteers had their eyes closed.

Large regions with increased activation were also seen in the cerebellum, including deep cerebellar nuclei, vermis, and hemispheres (Fig. 8). Of all of the cerebellar regions, the left cerebellar hemisphere was most heavily involved (Fig. $8 f-h$ ).

One distinct deactivated cluster was observed. This area was in the anterior part of the left medial temporal lobe, comprising parts of the amygdala and entorhinal cortex (Fig. 9).

\section{Discussion}

Clinical observations (Jochheim and Wahle, 1970) indicate that pathways exist between the brain or brainstem and thoracolumbar and/or sacral spinal cord that control sexual performance, including ejaculation, because urogenital function is severely impaired in patients with spinal cord injuries. The importance of these pathways is also emphasized by the fact that the main complaint of these patients is the inability to maintain a normal sex life rather than the inability to walk (Comarr, 1971). Not only ejaculation, but also the accompanying orgasmic sensations are gravely impaired or abolished in these patients (Sipski, 1998). Patients suffering from brain diseases such as cerebrovascular accidents (CVAs) or Parkinson's disease also experience sexual dysfunction (Monga et al., 1986; Sakakibara et al., 2001). These clinical observations emphasize the importance of the brain for sexual function.

The brain organization of human sexual behavior is a largely unresolved matter. The techniques to investigate the brain structures involved in mating behavior, used in rats, gerbils, cats, and other animals, are not applicable to humans. Modern neuroimaging techniques can detect brain structures that are specifically involved in ejaculation and orgasm, perhaps even better in humans than in animals. However, the spatial resolution in these neuroimaging techniques is much lower than most techniques used in animals.

Two previous studies have attempted to register brain activation in humans during ejaculation. An EEG study showed no remarkable changes in brain activity (Graber et al., 1985), whereas a single positron emission computed tomography study (Tiihonen et al., 1994) indicated a decrease in blood flow in all cortical areas, except for a significant increase in the right prefrontal cortex.

The design of the present PET study provides the time-scale resolution necessary to identify brain regions that are specifically activated during ejaculation and orgasm. Although fMRI has superior spatial and temporal resolution, we have applied PET 


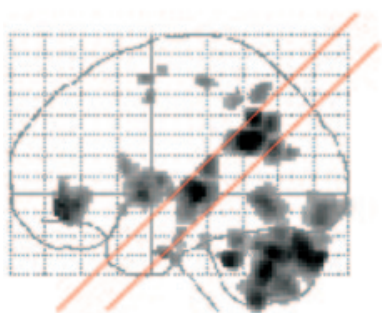

a..d
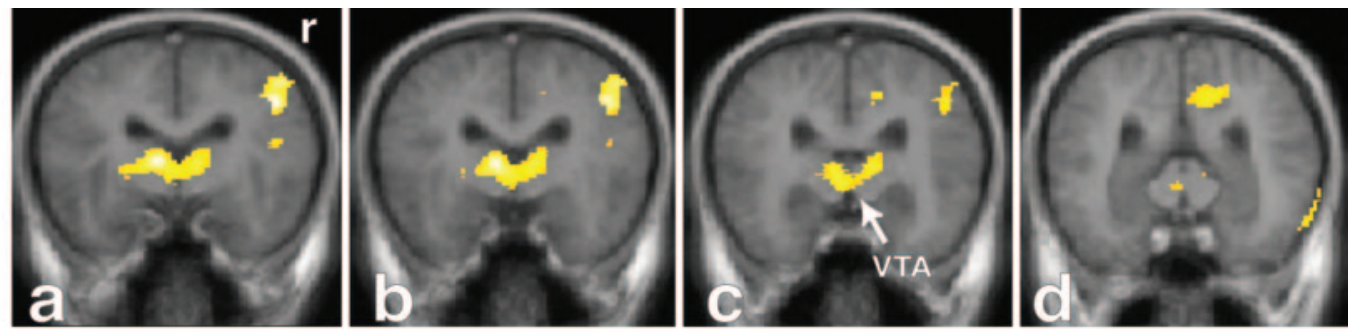

Figure 4. Increased $\mathrm{rCBF}$ is represented in oblique $\left(45^{\circ}\right)$ sections $(a-d)$ through the brain, to enable comparisons with sections obtained in experimental animals. The red lines on the glass brain on the left indicate the orientation and location of the sections. Activations are superimposed on the averaged MRI of the volunteers. The activated cluster contains the VTA (sections $a-d$ ). $r$, Right side.
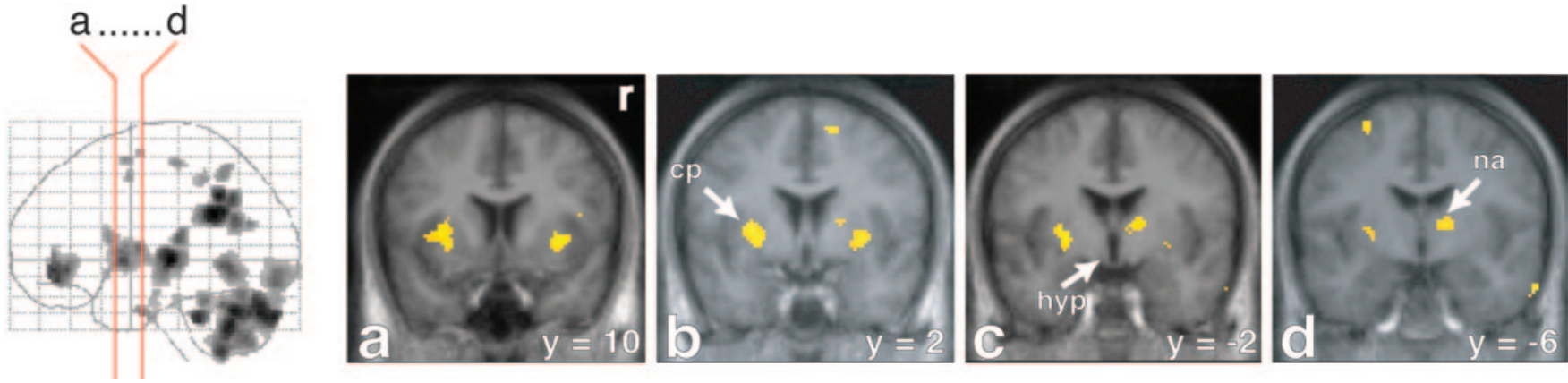

Figure 5. Activations in the basal ganglia and the anterior nucleus of the thalamus and absence of activation in the hypothalamus. Increases in rCBF are superimposed on the averaged MRI of the volunteers and are depicted in coronal sections (see the red lines on the glass brain on the left). Activations are found in the lateral putamen and perhaps the laterally adjoining claustrum and insula ( $c$; sections $a-c$ ). Note that in sections c and $d$, the anterior nucleus (na) of the thalamus is on the right side. Sections (b-d) demonstrate that in the hypothalamus (hyp) no activation is found. $y=$ -6 (means $6 \mathrm{~mm}$ posterior to the anterior commissure). r, Right side.
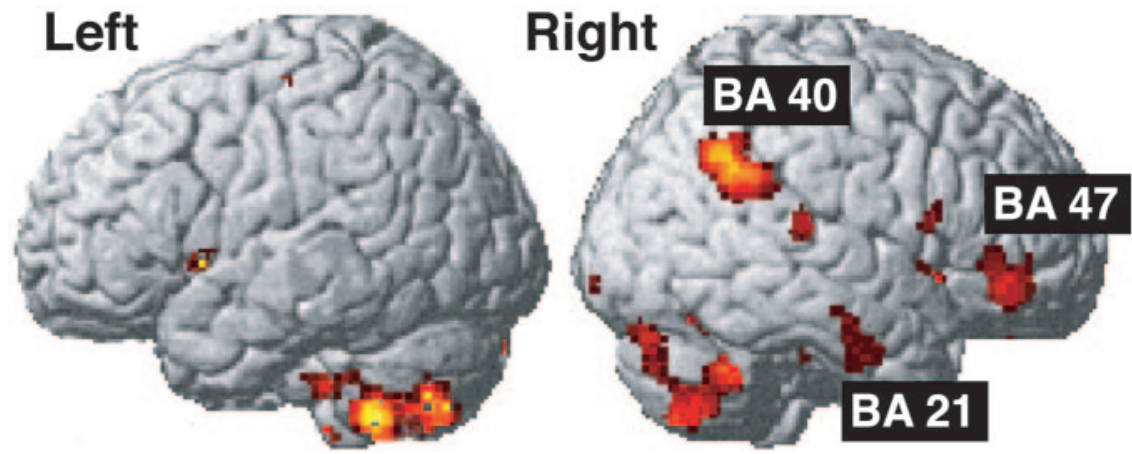

Figure 6. Activations in the cerebral cortex rendered onto a standard anatomical template (SPM99). Note that the cortical activations are almost exclusively on the right side.

scanning, because it is less sensitive to movement artifacts than fMRI (Turner et al., 1998). The various regions in which increased rCBF was found will be discussed successively.

\section{Mesodiencephalic junction}

The strongest activation was found in the mesodiencephalic transition zone. On the basis of the limited spatial resolution of the PET technique, it is not possible to distinguish specific brainregions within this area. The activated area at the mesodiencephalic junction comprises the VTA, subparafascicular nucleus, LCTF, and medial and ventral thalamus.

The VTA is located ventrally in the activated cluster. It contains the A10 dopaminergic cell group and plays a crucial role in a wide range of rewarding behaviors (McBride et al., 1999). Increased activation in the area of the VTA was also seen during cocaine (Breiter et al., 1997) and heroin rush (Sell et al., 1999). The finding that heroin addicts experience orgasmic pleasure with heroin usage (De Leon and Wexler, 1973; Mirin et al., 1980; Seecof and Tennant, 1986) fits with the notion that the VTA is the key element in both heroin and sexual orgasm. It also may explain why heroin addicts have a suppressed sex drive (Minz et al., 1974; Cicero et al., 1975), because heroin already heavily stimulates this region (Sell et al., 1999). The present findings may represent an anatomical substrate for the strongly reinforcing nature of sexual activity in humans. Because ejaculation introduces sperm into the female reproductive tract, it would be critical for reproduction of the species to favor ejaculation as a most rewarding behavior.

Another candidate for involvement in ejaculation is the dopaminergic A11 cell group, which is also located within the activated region in the mesodiencephalic transition zone (Pearson et al., 1990). The A11 cell group in rats (Skagerberg and Lindvall, 1985; Holstege et al., 1996), cats, and monkeys (Holstege et al., 1996) maintains direct projections to all parts of the gray matter throughout the length of the spinal cord, but its strongest projections are to the pelvic floor motoneurons in the upper sacral cord, the cremaster motoneurons in the L2 or L3 segments, and the T1-L2/3 sympathetic preganglionic motoneurons, including those innervating the genital organs.

An additional region that might play a role in ejaculation is the LCTF. In male rats, in which the LCTF comprises the SPFp, it is 

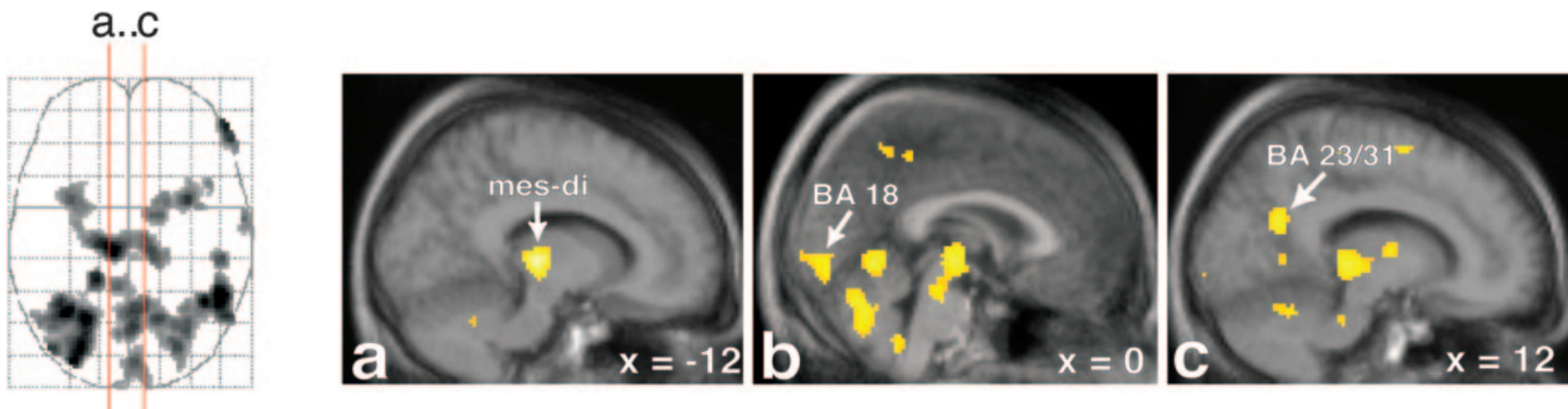

Figure 7. Sagittal view of the activations in midline cortical structures, the mesodiencephalic transition zone, and the cerebellum. Increased rCBF is represented in sagittal sections, of which the location is indicated by the red lines on the glass brain on the left. Activations are superimposed on the averaged MRI of the volunteers. In $b$ and $c$, activation in the secondary visual cortex (BA 18) and posterior cingulate/precuneus (BA23/31), respectively, can be found. Note in sections $a-c$ that the activation in the mesodiencephalic transition zone (mes-di) extends from the rostral midbrain into the ventral parts of the caudal thalamus. $x=-12$ (means $12 \mathrm{~mm}$ left to the intercommissural line).

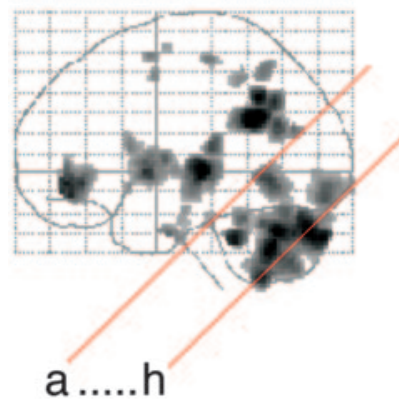

a.....h
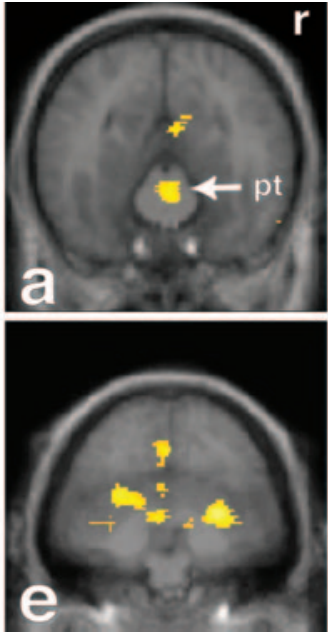
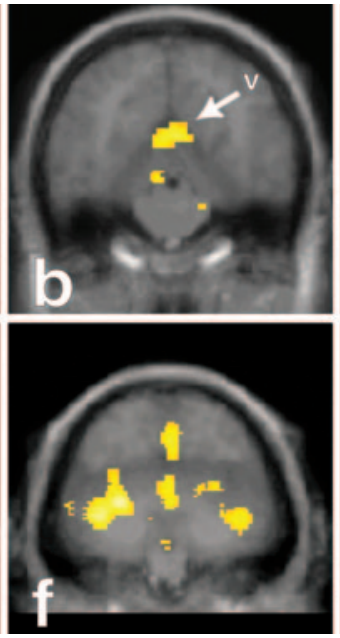
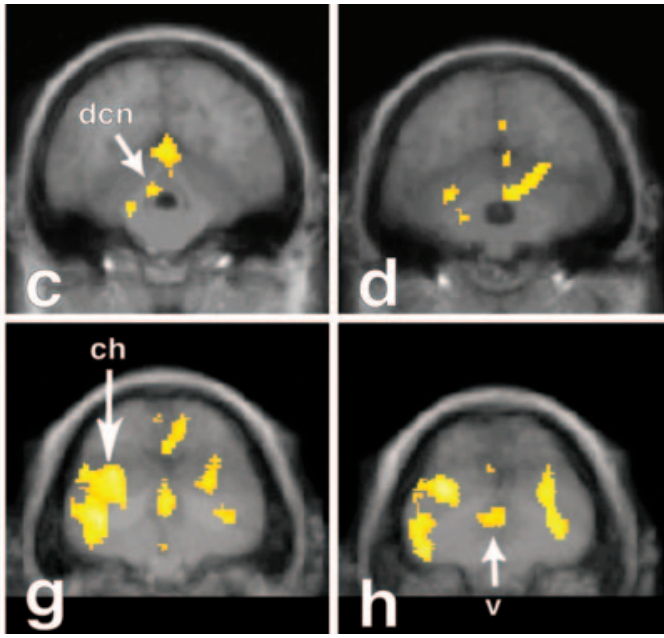

Figure 8. Activations in the cerebellum, brainstem, and occipital cerebral cortex. Increases in rCBF are superimposed on the averaged MRl of the volunteers and are depicted in oblique $\left(45^{\circ}\right)$ sections (see the red lines on the glass brain on the left). Cerebellar activations can be observed in the vermis (v; sections $b-h$ ), the cerebellar hemispheres (ch; sections $d-h$ ), and the deep cerebellar nuclei (dcn; sections $b-d$ ). Note that activation in the cerebellar hemisphere is more pronounced on the left than on the right side. Brainstem activation is present in the medial pontine tegmentum (section $a$ ), the lateral pontine tegmentum (sections $b$ and $c$ ), and in a region possibly involving the dorsal vagal nuclei and the solitary complex (sections $f$ and $g$ ). pt, Pontine tegmentum; r, right side.
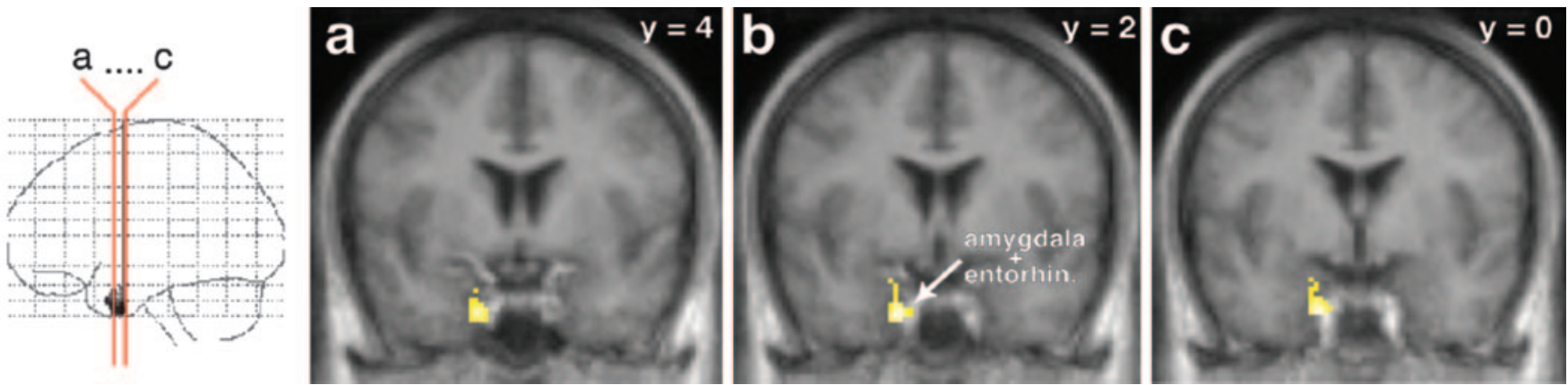

Figure 9. Deactivation in the anterior part of the left medial temporal lobe, comprising parts of the amygdala and entorhinal cortex (entorhin.). Decreases in rCBF are superimposed on the averaged MRI of the volunteers and are depicted in coronal sections (see the red lines on the glass brain on the left). The significance threshold was $p<0.001$ (uncorrected for multiple comparisons). $y=-2$ (means $2 \mathrm{~mm}$ caudal to the anterior commissure).

known to contain c-Fos-immunoreactive neurons after ejaculation (Baum and Everitt, 1992; Coolen et al., 1996). Lesions of the LCTF/SPFp have been reported to disrupt ejaculatory behavior in rats (Brackett and Edwards, 1984). The present results further corroborate the importance of the LCTF/SPFp in ejaculation. In rats, a galanin-containing group of cells in the third and fourth lumbar segments has been shown to send fibers through the spinal cord and brainstem to terminate in the LCTF/SPFp (Truitt et al., 2003). Ablation of these neurons by the selective toxin [Sar9, Met $\left(\mathrm{O}_{2}\right) 11$ substance $\mathrm{p}$-saporin resulted in complete disruption of ejaculatory behavior, while other components of sexual behavior remained intact (Truitt and Coolen, 2002). 
The pattern of thalamic activation might include both the midline and intralaminar nuclei, as well as the ventral part of the ventroposterior nuclei. The midline and intralaminar nuclei have been associated with generalized arousal (Kinomura et al., 1996), and the outer or "shell" portion of the ventroposterior thalamic nuclei has been associated primarily with visceral sensory responses (Bruggeman et al., 1994). Thus, the activation of the thalamus during ejaculation might reflect both the sensory experience as well as its arousing aspects.

\section{Striatum and cerebral cortex}

Strong activation in the lateral putamen and adjoining claustrum and insula, very similar to the present study, was found to be correlated with male sexual arousal (Redouté et al., 2000) and penile turgidity (Redouté et al., 2000; Arnow et al., 2002). The intense activation of the parietal lobe (BA 7 and 40) on the right side has been reported previously during sensory stimulation and may represent attention to the body surfaces that are being contacted (Coghill et al., 2001).

Activation of the precuneus (BA 31) may be related to the visual imagery that the volunteers used, because this region has been associated with memory-related imagery (Fletcher et al., 1995). The prefrontal activation (BA 47) on the right side was also found in successful micturition (Blok et al., 1997, 1998). Perhaps this part of Brodmann area 47 is the urogenital part of the prefrontal cortex, which plays a role in deciding whether or not micturition or ejaculation occurs at a particular time and place. The finding that the cortical activations are found almost exclusively on the right side corresponds with the results of Coslett and Heilman (1986), who reported that the frequency of sexual dysfunction is significantly higher after CVAs in the right than in the left hemisphere.

At first glance, the activation of the secondary visual cortex (BA 18) seems surprising, because the volunteers had their eyes closed. This activation might be explained, however, by the volunteers using visual imagery during the experiments. BA 18 is reported to be activated during visual hallucinations also (Silbersweig et al., 1995).

\section{Cerebellum}

Most prominent activation was found in large portions of the cerebellum during ejaculation. It is possible that this activity represents movements made by the volunteers during ejaculation, although these movements were relatively limited. The cerebellum, however, is not only involved in motor but also in emotional processing (Middleton and Strick, 2000). Our results correspond with reports of cerebellar activation during heroin rush (Sell et al., 1999), sexual arousal (Redouté et al., 2000), listening to pleasurable music (Blood and Zatorre, 2001), and monetary reward (Martin-Sölch et al., 2001). Moreover, clinical studies have revealed that large lesions of the cerebellar vermis in humans may cause blunting of affect and inappropriate behavior (Schmahmann and Sherman, 1998; Stone et al., 2001). Also a large lesion in the cerebellar hemisphere has been shown to cause emotional flattening, increased risk taking, and impaired autonomic activity to negative and positive reinforcement (Annoni et al., 2003).

\section{Absence of activation in MPOA and BNST}

The amygdala, the bed nucleus of the stria terminalis, and especially the MPOA, which were most closely associated with ejaculation in rat c-Fos (Baum and Everitt, 1992) and lesion studies (Brackett and Edwards, 1984), did not show any increased rCBF
(Fig. 5c). In rodents, the MPOA is considered critical for sexual behavior, because rat studies (Hansen et al., 1982; Brackett and Edwards, 1984; Baum and Everitt, 1992) suggest that it plays an important role in arousal and ejaculation. In primates, however, none of these regions show increased c-Fos in males that ejaculated compared with unmated males (Michael et al., 1999). Our data support the latter findings. Perhaps in primates the MPOA is not involved in ejaculation but plays a role in creating the proper conditions for sexual behavior.

\section{Deactivations in amygdala and entorhinal cortex}

The only cluster of deactivation that could be found was in parts of the amygdala and entorhinal cortex (Fig. 9), albeit at a threshold of $p<0.001$ (uncorrected for multiple comparisons). From rodents to primates, the amygdala is well known for its role in vigilance and fear. Neuroimaging experiments have confirmed these observations in humans by demonstrating increased amygdala activation by fearful stimuli (for review, see Davis and Whalen, 2002; Rauch et al., 2003). Our results correspond with the finding of Redouté et al. (2000), who found that the medial temporal lobe showed a negative correlation with penile tumescence and sexual arousal. In other neuroimaging studies, decreased amygdala activity was found when volunteers who were deeply in love viewed pictures of their loved ones (Bartels and Zeki, 2002). Breiter et al. (1997) showed a similar deactivation when volunteers experienced cocaine rush, and they suggested that amygdala deactivation correlates with euphoric psychological states. The orgasmic experience during ejaculation in the present study might also be considered as an example of such euphoric states.

\section{Epilogue}

Understanding the inter-relationships of the neuronal populations that are activated during ejaculation will provide an important challenge for future studies. The recent enormous success of sexual potency-increasing drugs is a reflection of the magnitude of problems in the field of sexual health. To confront problems such as impotence and premature ejaculation, it is crucial to understand how the human brain controls penile erection, sexual arousal, and ejaculation. The present study for the first time reveals brain regions involved in human male ejaculation and orgasm. We expect that future studies will disclose more precisely the role of these structures and the neurotransmitters and neuromodulators that are involved. The results will have important implications for our ability to influence these specific brain regions, to improve sexual function and satisfaction in men.

\section{References}

Annoni JM, Ptak R, Caldara-Schnetzer AS, Khateb A, Pollermann BZ (2003) Decoupling of autonomic and cognitive emotional reactions after cerebellar stroke. Ann Neurol 53:654-658.

Arnow BA, Desmond JE, Banner LL, Glover GH, Solomon A, Polan ML, Lue TF, Atlas SW (2002) Brain activation and sexual arousal in healthy, heterosexual males. Brain 125:1014-1023.

Bartels A, Zeki S (2000) The neural basis of romantic love. NeuroReport 17:3829-3834.

Baum MJ, Everitt BJ (1992) Increased expression of c-fos in the medial preoptic area after mating in male rats: role of afferent inputs from the medial amygdala and central tegmental field. Neuroscience 50:627-646.

Blok BFM, Willemsen ATM, Holstege G (1997) A PET study on the control of micturition and urine storage in humans. Brain 120:111-121. 
Blok BFM, Sturms LM, Holstege G (1998) Brain activation during micturition in women. Brain 121:2033-2042.

Blood AJ, Zatorre RJ (2001) Intensely pleasurable responses to music correlate with activity in brain regions implicated in reward and emotion. Proc Natl Acad Sci USA 98:11818-11823.

Bocher M, Chisin R, Parag Y, Freedman N, Meir Weil Y, Lester H, Mishani E, Bonne O (2001) Cerebral activation associated with sexual arousal in response to a pornographic clip: a ${ }^{15} \mathrm{O}-\mathrm{H}_{2} \mathrm{O}$ PET study in heterosexual men. NeuroImage 14:105-117.

Brackett NL, Edwards DA (1984) Medial preoptic connections with the midbrain tegmentum are essential for male sexual behavior. Physiol Behav 32:79-84.

Breiter HC, Gollub RL, Weisskoff RM, Kennedy DN, Makris N, Berke JD, Goodman JM, Kantor HL, Gastfriend DR, Riorden JP, Mathew RT, Rosen BR, Hyman SE (1997) Acute effects of cocaine on human brain activity and emotion. Neuron 19:591-611.

Bruggemann J, Vahle-Hinz C, Kniffki KD (1994) Projections from the pelvic nerve to the periphery of the cat's thalamic ventral posterolateral nucleus and adjacent regions of the posterior complex. J Neurophysiol 72:2237-2245.

Cicero TJ, Bell RD, Wiest WG, Allison JH, Polakoski K, Robins E (1975) Function of the male sex organs in heroin and methadone users. N Engl J Med 292:882-887.

Coghill RC, Gilron I, Iadarola MI (2001) Hemispheric lateralization of somatosensory processing. J Neurophysiol 85:2602-2612.

Comarr AE (1971) Sexual concepts in traumatic cord and cauda equina lesions. J Urol 106:375-378.

Coolen LM, Peters HJ, Veening JG (1996) Fos immunoreactivity in the rat brain following consummatory elements of sexual behavior: a sex comparison. Brain Res 738:67-82.

Coslett HB, Heilman KM (1986) Male sexual function. Impairment after right hemisphere stroke. Arch Neurol 43:1036-1039.

Davis M, Whalen PJ (2001) The amygdala: vigilance and emotion. Mol Psychiatry 6:13-34.

De Leon G, Wexler HK (1973) Heroin addiction: its relation to sexual behavior and sexual experience. J Abnorm Psychol 81:36-38.

Fletcher PC, Frith CD, Baker SC, Shallice T, Frackowiak RS, Dolan RJ (1995) The mind's eye: precuneus activation in memory-related imagery. NeuroImage 2:195-200.

Friston KJ, Ashburner J, Poline J-B, Frith CD, Heather JD, Frackowiak RSJ (1995a) Spatial registration and normalisation of images. Hum Brain Mapp 2:165-189.

Friston KJ, Holmes AP, Worsley KJ, Poline J-B, Frith CD, Frackowiak RSJ (1995b) Statistical parametric mapping in functional imaging: a general approach. Hum Brain Mapp 2:189-210.

Gil-Vernet Jr JM, Alvarez-Vijande R, Gil-Vernet A, Gil-Vernet JM (1994) Ejaculation in men: a dynamic endorectal ultrasonographical study. Br J Urol 73:442-448.

Graber B, Rohrbaugh JW, Newlin DB, Varner JL, Ellingson RJ (1985) EEG during masturbation and ejaculation. Arch Sex Behav 14:491-503.

Hansen S, Kohler C, Goldstein M, Steinbusch HV (1982) Effects of ibotenic acid-induced neuronal degeneration in the medial preoptic area and the lateral hypothalamic area on sexual behavior in the male rat. Brain Res 239:213-232.

Heeb MM, Yahr P (1996) c-fos immunoreactivity in the sexually dimorphic area of the hypothalamus and related brain regions of male gerbils after exposure to sex-related stimuli or performance of specific sexual behaviors. Neuroscience 72:1049-1071.

Heeb MM, Yahr P (2000) Cell-body lesions of the posterodorsal preoptic nucleus or posterodorsal medial amygdala, but not the parvicellar subparafascicular thalamus, disrupt mating in male gerbils. Physiol Behav 68:317-331.

Holstege JC, VanDijken H, Buijs RM, Goedknegt H, Gosens T, Bongers CM (1996) Distribution of dopamine immunoreactivity in the rat, cat, and monkey spinal cord. J Comp Neurol 376:631-652.

Jochheim KA, Wahle H (1970) A study on sexual function in 56 male patients with complete irreversible lesions of the spinal cord and cauda equina. Paraplegia 8:166-172.

Jueptner M, Weiller C (1995) Rev: does measurement of rCBF reflect synaptic activity? Implications for PET and fMRI. NeuroImage 2:148-156.
Karama S, Lecours AR, Leroux JM, Bourgouin P, Beaudoin G, Joubert S, Beauregard M (2002) Areas of brain activation in males and females during viewing of erotic film excerpts. Hum Brain Mapp 16:1-16.

Kinomura S, Larsson J, Gulyas B, Roland PE (1996) Activation by attention of the human reticular formation and thalamic intralaminar nuclei. Science 271:512-515.

Kovács KJ (1998) c-Fos as a transcription factor: a stressful (re)view from a functional map. Neurochem Int 33:287-297.

Mai JK, Assheuer J, Paxinos G (1997) Atlas of the human brain. San Diego: Academic.

Martin-Sölch C, Magyar S, Kunig G, Missimer J, Schultz W, Leenders KL (2001) Changes in brain activation associated with reward processing in smokers and nonsmokers. Exp Brain Res 139:278-286.

McBride WJ, Murphy JM, Ikemoto S (1999) Localization of brain reinforcement mechanisms: intracranial self-administration and intracranial place-conditioning studies. Behav Brain Res 101:129-152.

McKenna K (1999) The brain is the master organ in sexual function: central nervous system control of male and female sexual function. Int J Impot Res 11:48-55.

Michael RP, Clancy AN, Zumpe D (1999) Effects of mating on c-fos expression in the brains of male macaques. Physiol Behav 66:591-597.

Middleton FA, Strick PL (2000) Basal ganglia and cerebellar loops: motor and cognitive circuits. Brain Res Brain Res Rev 31:236-250.

Mintz J, O’Hare K, O’Brien CP, Goldschmidt J (1974) Sexual problems of heroin addicts. Arch Gen Psychiatry 31:700-703.

Mirin SM, Meyer RE, Mendelson JH, Ellingboe J (1980) Opiate use and sexual function. Am J Psychiatry 137:909-915.

Monga TN, Lawson JS, Inglis J (1986) Sexual dysfunction in stroke patients. Arch Phys Med Rehabil 67:19-22.

Pearson J, Halliday G, Sakamoto N, Michel J-P (1990) Catecholaminergic neurons. In: The human nervous system (Paxinos G, ed), pp 1023-1049. San Diego: Academic.

Rauch SL, Shin LM, Wright CI (2003) Neuroimaging studies of amygdala function in anxiety disorders. Ann NY Acad Sci 985:389-410.

Redouté J, Stoleru S, Gregoire MC, Costes N, Cinotti L, Lavenne F, Le Bars D, Forest MG, Pujol JF (2000) Brain processing of visual sexual stimuli in human males. Hum Brain Mapp 11:162-177.

Reinders AATS, Willemsen ATM, Georgiadis JR, Hovius M, Paans AMJ, DenBoer JA (2002) Interscan displacement-induced variance in PET activation data is excluded by a scan-specific attenuation correction. NeuroImage 17:1844-1853.

Sakakibara R, Shinotoh H, Uchiyama T, Sakuma M, Kashiwado M, Yoshiyama M, Hattori T (2001) Questionnaire-based assessment of pelvic organ dysfunction in Parkinson's disease. Auton Neurosci 92:76-85.

Schmahmann JD, Sherman JC (1998) The cerebellar cognitive affective syndrome. Brain 121:561-579.

Seecof R, Tennant Jr FS (1986) Subjective perceptions to the intravenous "rush" of heroin and cocaine in opioid addicts. Am J Drug Alcohol Abuse 12:79-87.

Sell LA, Morris J, Bearn J, Frackowiak RS, Friston KJ, Dolan RJ (1999) Activation of reward circuitry in human opiate addicts. Eur J Neurosci 11:1042-1048.

Silbersweig DA, Stern E, Frith CD, Cahill C, Schnorr L, Grootoonk S, Spinks T, Clark J, Frackowiak R, Jones T (1993) Detection of thirty-second cognitive activations in single subjects with positron emission tomography: a new low-dose $\mathrm{H}_{2}{ }^{15} \mathrm{O}$ regional cerebral blood flow three-dimensional imaging technique. J Cereb Blood Flow Metab 13:617-629.

Silbersweig DA, Stern E, Schnorr L, Frith CD, Ashburner J, Cahill C, Frackowiak RS, Jones T (1994) Imaging transient, randomly occurring neuropsychological events in single subjects with positron emission tomography: an event-related count rate correlational analysis. J Cereb Blood Flow Metab 14:771-782.

Silbersweig DA, Stern E, Frith C, Cahill C, Holmes A, Grootoonk S, Seaward J, McKenna P, Chua SE, Schnorr L, Jones T, Frackowiak RSJ (1995) A functional neuroanatomy of hallucinations in schizophrenia. Nature 378:176-179.

Sipski ML (1998) Sexual functioning in the spinal cord injured. Int J Impot Res 10 [Suppl 2]:128-130.

Skagerberg G, Lindvall O (1985) Organization of diencephalic dopamine neurons projecting to the spinal cord. Brain Res 342:340-351. 
Small DM, Zatorre RJ, Dagher A, Evans AC, Jones-Gotman M (2001) Changes in brain activity related to eating chocolate: from pleasure to aversion. Brain 24:1720-1733.

Stoleru S, Gregoire MC, Gerard D, Decety J, Lafarge E, Cinotti L, Lavenne F, Le Bars D, Vernet-Maury E, Rada H, Collet C, Mazoyer B, Forest MG, Magnin F, Spira A, Comar D (1999) Neuroanatomical correlates of visually evoked sexual arousal in human males. Arch Sex Behav 28:1-21.

Stone J, Smith L, Watt K, Barron L, Zeman A (2001) Incoordinated thought and emotion in spinocerebellar ataxia type 8. J Neurol 248:229-232.

Talairach J, Tournoux P (1988) Co-planar atlas of the human brain. New York: Springer.
Tiihonen J, Kuikka J, Kupila J, Partanen K, Vainio P, Airaksinen J, Eronen M, Hallikainen T, Paanila J, Kinnunen I, Huttunen J (1994) Increase in cerebral blood flow of right prefrontal cortex in man during orgasm. Neurosci Lett 170:241-243.

Truitt WA, Coolen LM (2002) Identification of a potential ejaculation generator in the spinal cord. Science 297:1566-1569.

Truitt WA, Shipley MT, Veening JG, Coolen LM (2003) Activation of a subset of lumbar spinothalamic neurons after copulatory behavior in male but not female rats. J Neurosci 23:325-331.

Turner R, Howseman A, Rees GE, Josephs O, Friston K (1998) Functional magnetic resonance imaging of the human brain: data acquisition and analysis. Exp Brain Res 123:5-12. 